\title{
高粘度液によるカーボンナノチューブの解繊効果
}

\author{
小橋 和文*，関口 貴子，山田 健郎，岡崎 俊也
}

\section{Unravelling Effect of Carbon Nanotube Powders by Highly Viscous Liquids}

\author{
Kazufumi Kobashi*, Atsuko Sekiguchi, Takeo Yamada and Toshiya Okazaki
}

Received 29 March 2019; Accepted 3 July 2019

\begin{abstract}
Toward industrial applications of commercialized carbon nanotubes (CNT), fully utilizing the intrinsic CNT properties is challenging due to the quality deterioration and the uncontrolled states through dispersion processes in matrices. Therefore we propose a predispersion step of CNTs prior to distributing them into matrices, clarifying the unravelling effect of CNT powders by various liquids with different viscosities like alcohols, silicone oils, ionic liquid, ketone, hydrocarbons, aprotic polar solvents, and water. Regardless of solvent polarity, liquids with higher viscosities led to more unravelled CNT particles, reaching up to an approximately ten thousand times higher particle number than one before the dispersion.
\end{abstract}

Keywords: Carbon nanotube, Dispersion, Predispersion, Unravelling, Viscous liquid.

\section{1. 緒言}

近年，カーボンナノチューブ（CNT）実用化研究が進 み, 多様な市販カーボンナノチューブ (CNT) によって Li イオン電池導電助剤をはじめ, 耐環境性塗料, シート 系熱界面材料, 耐熱性ゴムシール材, 伸縮性ひずみセン サー，スポーツ用品などの実用化事例が見られるように なった[1]。このような CNT の産業応用を進めるには, その共通基盤となる技術が重要であり, 多くの用途開発 で分散および分散体評価手法の開発が望まれている。

これまでCNT を液, ゴム, 樹脂, 金属などの媒体に超 音波処理, ボールミル, 溶融混錬などにより分散し, CNT 単独および複合部材の開発が多く試みられてきた $[2,3]$ 。 しかしながら, CNT 分散工程で品質の劣化や粗大な解繊 不良物が発生し, CNT 本来の特性を引き出すのは容易で はなかった。これは as-grown CNT 粉体がサイズに分布の ある $(\mu \mathrm{m} \sim \mathrm{cm}$ スケール $)$ 多様な粒子から形成されてい て, 各粒子で分散の進行が異なるためと考えられる。そ こで, 本研究では初期の CNT 大粒子を分布の少ない小粒 子にしてから所望の媒体に分散し，本来の特性が活用で きるよう, さまざまな粘度の液体で CNT 粉体の解繊を検 討した。

国立研究開発法人 産業技術総合研究所ナノチューブ実用化研究セ ンター

（テ 305-8565 茨城県つくば市東 1-1-1 中央第 5)

National Institute of Advanced Industrial Science and Technology (AIST)

(Central 5, 1-1-1 Higashi, Tsukuba, Ibaraki 305-8565, Japan)

* Corresponding Author kobashi-kazufumi@aist.go.jp

\section{2. 実験方法}

CNT 試料としてスーパーグロース法によって合成され た単層 CNT 粉体[4]を用い, 溶媒として種々の粘度 (0.数 〜 $1400 \mathrm{mPa} \cdot \mathrm{s}$ ）を有する液体を用いた（アルコール類, シリコーンオイル, イオン液体, ケトン類, 炭化水素, 非プロトン性極性溶媒, 水)。水を用いた場合の分散剤と してデオキシコール酸ナトリウム（SDOC）を $5 \mathrm{wt} \%$ で 使用した。CNT 粉体の解繊は濃度 $0.01 \mathrm{wt} \%$ （CNT $0.01 \mathrm{~g}$, 溶媒 $99.99 \mathrm{~g}$ を底面内径 $6 \mathrm{~cm}$ の $300 \mathrm{~mL}$ ビーカー に投入) で長さ $5 \mathrm{~cm}$ 三角柱型擋挥子を用いて $500 \mathrm{rpm}$ で $3 \mathrm{~h}$, 室温で行った。得られた CNT 分散液に含まれる分 散体の形態をデジタル顕微鏡（VHX-1000, キーエンス 社）により液中で直接観察した。また，分散液に含まれ る分散体の数をフロー型の湿式画像解析粒度分布計 (IF-400nano, ジャスコインタナショナル社, 測定範囲 $0.8 \mu \mathrm{m}$ 約 $3 \mathrm{~mm}, 1 \mathrm{~mm}$ 厚さのスペーサーを使用したフ

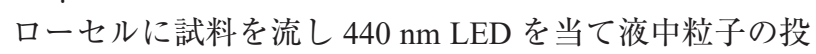
影画像を取得）で測定し, CNT 粉体の解繊度合いを評価 した。数千〜数万個の粒子を測定し, 分散液 $1 \mathrm{~mL}$ あた りに含まれる分散体の数を算出して解繊度合いの指標と して用いた。用いた溶媒の粘度はパラレルプレート型レ オメータ（MCR 102，アントンパール社）により測定した。

\section{3. 実験結果および考察}

産業応用における CNT 粉体の分散工程では CNT 濃度 が 0 . 数〜数\%で行われる場合が多いが, 本研究では液体 粘度が CNT 解繊におよぼす効果を明らかにするため, 


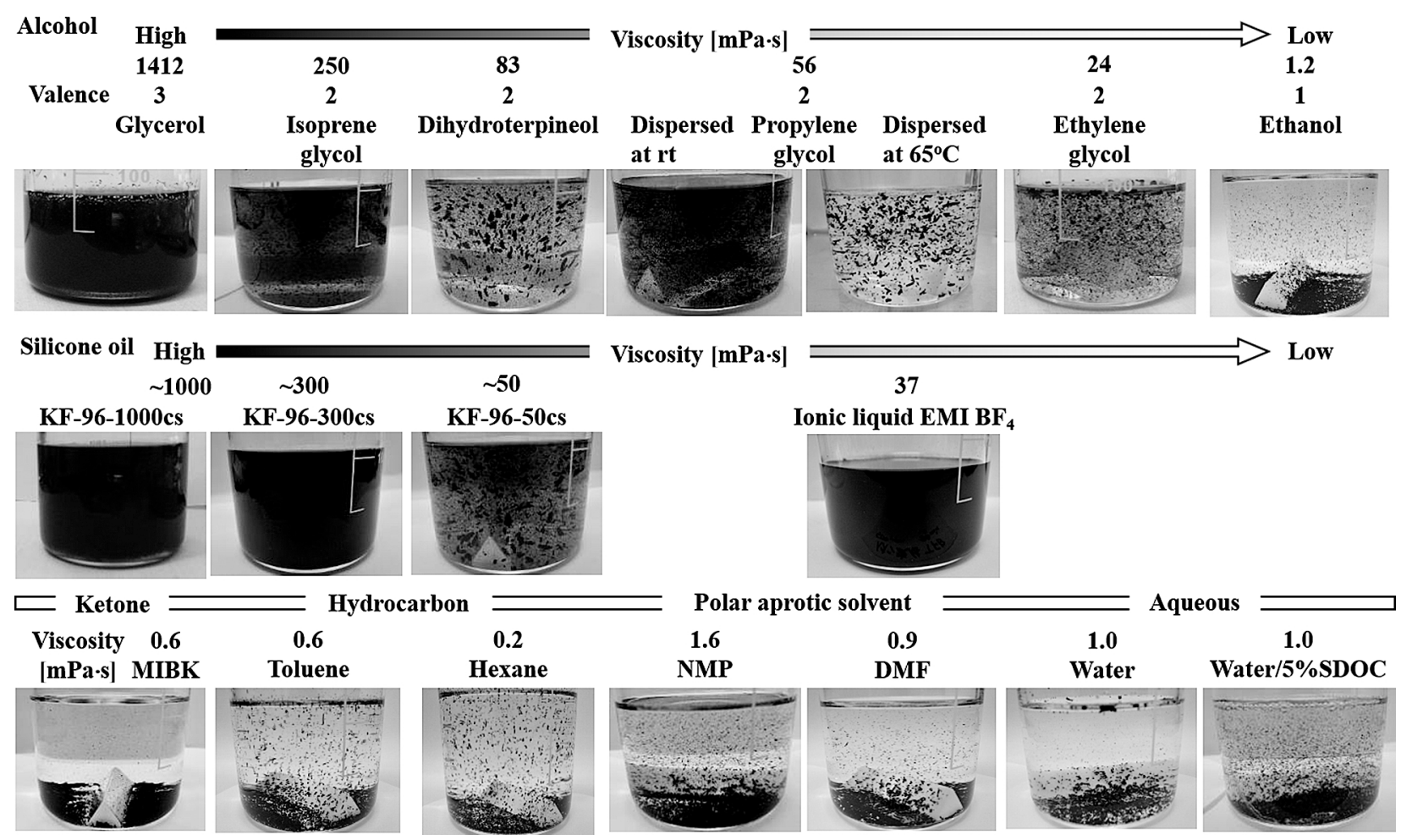

Fig. 1 Photos of CNT dispersions agitated for $3 \mathrm{~h}$ in various liquids with different viscosities

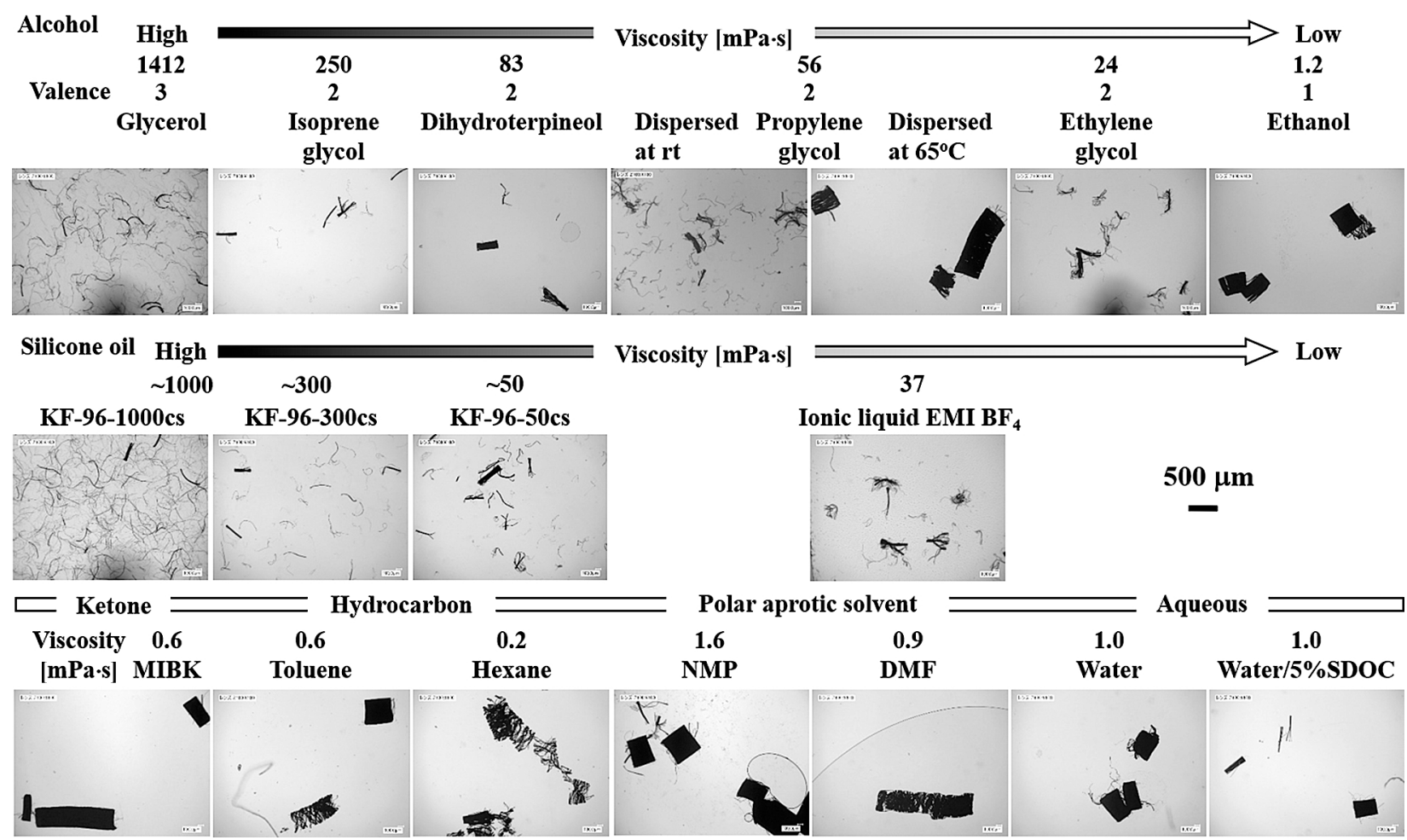

Fig. 2 Digital microscope images of CNT particles in the dispersions agitated for $3 \mathrm{~h}$ in various liquids with different viscosities. The scale bar $500 \mu \mathrm{m}$ is shown on the right side

CNT 濃度を $0.01 \mathrm{wt} \%$ と低く設定した。このような低濃度 では CNT 粉体中の個々の粒子どうしが接触しにくいた め, 解繊に対する液体粘度の影響が表れやすいと考えら
れる。分散手法としては, 種々の粘度を有する液体中で 擋拌子を用いる非常にシンプルな手法を選択した。用い た CNT 粉体は数百 $\mu \mathrm{m}$ サイズの CNT 配向集合体で[1], 
分散工程により細分化され網目状の分散体となることが 報告されている[5-9]。

擋汼子による分散を行った結果，用いた液体の種類に よって CNT 粉体の解繊度合いは異なった。まず, 極性の 大きいアルコール類を用いて分散を行ったところ，その 価数によらず粘度が高い溶媒ほど，均一な黒色を呈した 分散液が得られた。その様子を Fig. 1 の上段に示す。プ ロピレングリコールを用いた場合は，室温で分散すると 黒色の分散液が得られたが， $65^{\circ} \mathrm{C}$ で溶媒を低粘度化させ 分散すると, 黑色の分散液は得られなかった。一方, 極 性の小さいシリコーンオイルを用いて分散すると，粘度 の高いものほど均一な黒色を呈した分散液が得られた。 その様子を Fig. 1 の中段に示す。また, CNT の優れた分 散媒として知られ, 粘度の高いイオン液体でも均一な黒 色の分散液が得られた。これらの黒色を呈した分散液は 摚拌後, 数時間経つと再凝集がいくらか起こるが, 再度 擋拌するといずれも数秒で黒色の安定な状態に戻った。 しかしながら, Fig.1の下段に示すように粘度が低いケ トン類, 炭化水素, 非プロトン性極性溶媒, 水を用いる と, いずれも黒色の分散液は得られなかった。さらに, 分散剤 SDOC を用いた水中でも同様な結果であった。こ の分散で用いた非プロトン性極性溶媒の NMP, DMF は CNT のよい分散媒として知られているが $[10,11]$, 興味深 いことにCNT の解繊はさほど進まなかった。以上の結果 から, CNT 粉体の解繊には液体粘度が著しい影響を与え ることがわかった。

次にこれらの分散液中の分散体の形態観察を行い，解 繊度合いを検討した。低粘度の液体を用いると，分散前 の CNT 粉体に見られる長さが約 $500 \mu \mathrm{m}$ ，幅が数百 $\mu \mathrm{m}$
の CNT 配向集合体が見られ, 解繊が進んでいない様子が 観察された。一方, Fig. 2 に示すように用いる液体の粘 度が高いほど, CNT 粉体がより細分化され解繊された分 散体が見られ, 分散液の外観 (Fig. 1) に対応した。さら に, フロー型の湿式画像解析粒度分布計で分散液を測定 したところ，Fig. 3 に示すように高粘度の液体ほど，液 中の分散体数が増大することがわかり（分散前と比べる と最大で〜10000 倍), 高粘度液による CNT 解繊効果が 定量的に裏付けられた。用いた液体の Table 1 に示す表 面張力, 溶解度パラメー夕, 密度などのほか物性值[1216]は解繊度合いに対してあまり相関がなく, この初期の 解繊では粘度による効果がきわめて高かった。

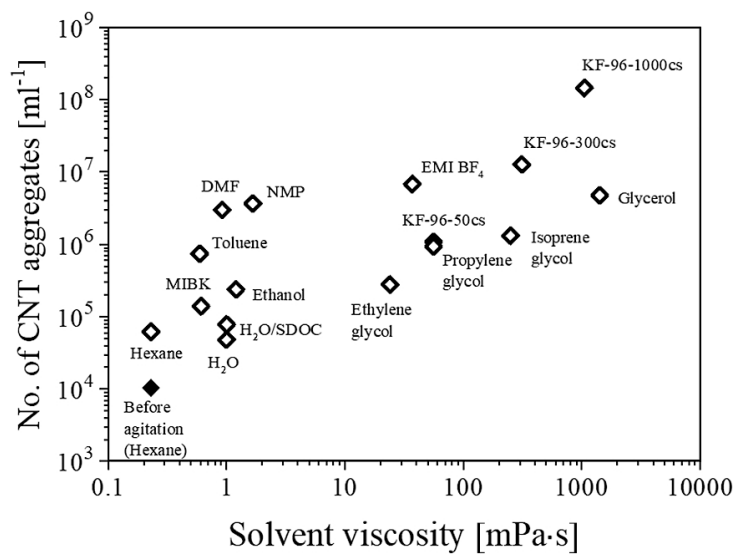

Fig. 3 Correlation between the liquid viscosities and the CNT particle numbers in the dispersion agitated for $3 \mathrm{~h}$ in the various liquids

Table 1 Physical properties of solvents used for unraveling CNT powders

\begin{tabular}{|c|c|c|c|c|c|c|c|}
\hline \multicolumn{2}{|c|}{ Solvent } & \multirow{2}{*}{$\begin{array}{c}\mathrm{mp} \\
{\left[{ }^{\circ} \mathrm{C}\right]} \\
-114\end{array}$} & \multirow{2}{*}{$\begin{array}{c}\text { bp } \\
{\left[{ }^{\circ} \mathrm{C}\right]}\end{array}$} & \multirow{2}{*}{$\begin{array}{c}\begin{array}{c}\text { Viscosity } \\
{[\mathrm{mPa} \cdot \mathrm{s}]}\end{array} \\
1.2\end{array}$} & \multirow{2}{*}{$\begin{array}{c}\text { Surface tension } \\
{[\mathrm{mN} / \mathrm{m}]}\end{array}$} & \multirow{2}{*}{$\begin{array}{c}\begin{array}{c}\text { Density } \\
{\left[\mathrm{g} / \mathrm{cm}^{3}\right]}\end{array} \\
0.78\end{array}$} & \multirow{2}{*}{$\begin{array}{c}\begin{array}{c}\text { Solubility parameter } \\
{\left[\mathrm{MPa}^{1 / 2}\right]}\end{array} \\
26.13\end{array}$} \\
\hline Monohydroxy alcohol & Ethanol & & & & & & \\
\hline \multirow{4}{*}{ Dihydroxy alcohol } & Ethylene glycol & -13 & 198 & 24 & 48.43 & 1.11 & 33.70 \\
\hline & Propylene glycol & -59 & 188 & 56 & 45.6 & 1.04 & 29.52 \\
\hline & Dihydroterpineol & - & 211 & 83 & - & 0.91 & - \\
\hline & Isoprene glycol & - & 203 & 250 & 70 & 0.98 & - \\
\hline Trihydroxy alcohol & Glycerol & 18 & - & 1412 & 64.0 & 1.26 & 34.12 \\
\hline \multirow{3}{*}{ Silicone oil } & KF-96-50cs & - & - & $56^{\#}$ & $20.8^{\bullet}$ & 0.96 & $14.9-15.59$ \\
\hline & KF-96-300cs & - & - & $311^{\#}$ & $21.1^{\bullet}$ & 0.97 & $14.9-15.59^{\circ}$ \\
\hline & KF-96-1000cs & - & - & $1051^{\#}$ & $21.2^{\bullet}$ & 0.97 & $14.9-15.59^{\diamond}$ \\
\hline Ionic liquid & $\mathrm{EMI} \mathrm{BF}_{4}$ & 13 & - & 37 & 44.3 & 1.28 & $26.11^{\bullet}$ \\
\hline Ketone & MIBK & -84 & 116 & 0.61 & 23.64 & 0.80 & 16.97 \\
\hline \multirow{2}{*}{ Hydrocarbon } & Hexane & -95 & 69 & 0.23 & 18.40 & 0.68 & 14.90 \\
\hline & Toluene & -95 & 111 & 0.59 & 28.52 & 0.87 & 18.32 \\
\hline \multirow{2}{*}{ Polar aprotic solvent } & DMF & -61 & 153 & 0.92 & 36.76 & 0.95 & 23.95 \\
\hline & NMP & -24 & 202 & 1.67 & 40.79 & 1.03 & 22.96 \\
\hline Water & & 0 & 100 & 1.0 & 72.80 & 1.0 & 47.82 \\
\hline
\end{tabular}

$\mathrm{mp}$, bp, viscsity $\left(20^{\circ} \mathrm{C}\right)$, surface tension $\left(20^{\circ} \mathrm{C}\right)$, density: Cited from SDS and technical reports from the suppliers.

DataPhysics Instruments $\mathrm{GmbH}$ technical report, [12,13], \# measured values of viscosity at shear rate of $2 \mathrm{~s}^{-1}\left(25^{\circ} \mathrm{C}\right)$.

- Surface tension values at $25^{\circ} \mathrm{C}$.

Solubility parameter: Cited from Hansen SP $\delta_{\text {total }}[14], \stackrel{\bullet}{\bullet}$ Hildebrand SP $\delta[15,16]$. 


\section{4. 結 言}

CNT 用途開発において, 共通課題となっている分散の 解決手段として, 我々は高粘度液による解繊をプレ分散 として提案する。さまざまな液体を用いて CNT 粉体の分 散を検討した結果, 液体粘度が高いほど解繊が進み, 分
散体の数が増大し高粘度液による解繊効果が明らかと なった。

この成果は, 国立研究開発法人新エネルギー・産業技 術総合開発機構（NEDO）の委託業務の結果得られたも のである。

\section{References}

[1] The Global Market for Carbon Nanotubes, Future Market, Inc. (UK) (2019) 29-53.

[2] M. Moniruzzaman, K. I. Winey, Polymer nanocomposites containing carbon nanotubes, Macromolecules 39 (2006) 5194-5205.

[3] M. J. Green, N. Behabtu, M. Pasquali, W. W. Adams, Nanotubes as polymers, Polymer 50 (2009) 4979-4997.

[4] K. Hata, D. N. Futaba, K. Mizuno, T. Namai, M. Yumura, S. Iijima, Water-assisted highly efficient synthesis of impurityfree single-walled carbon nanotubes, Science 306 (2004) 1362-1364.

[5] S. Ata, K. Kobashi, M. Yumura, K. Hata, Mechanically durable and highly conductive elastomeric composites from long single-walled carbon nanotubes mimicking the chain structure of polymers, Nano Lett. 12 (2012) 2710-2716.

[6] K. Kobashi, S. Ata, T. Yamada, D. N. Futaba, M. Yumura, K. Hata, A dispersion strategy: dendritic carbon nanotube network dispersion for advanced composites, Chem. Sci. 4 (2013) 727-733.

[7] H. Yoon, M. Yamashita, S. Ata, D. N. Futaba, T. Yamada, K. Hata, Controlling exfoliation in order to minimize damage during dispersion of long SWNTs for advanced composites, Sci. Rep. 4 (2014) 3907.

[8] Y. Imai, D. Shimamoto, Y. Hotta, Effect of wet jet milling of carbon nanotube on electrical properties of polymer nanocomposites, Mater. Chem. Phys. 148 (2014) 1178-1183.

[9] K. Kobashi, S. Ata, T. Yamada, D. N. Futaba, K. Hata,
Controlling the structure of arborescent carbon nanotube networks for advanced rubber composites, Compos. Sci. Technol. 163 (2018) 10-17.

[10] S. D. Bergin, V. Nicolosi, P. V. Streich, S. Giordani, Z. Sun, A. H. Windle, P. Ryan, N. P. P. Niraj, Z.-T. T. Wang, L. Carpenter, W. J. Blau, J. J. Boland, J. P. Hamilton, J. N. Coleman, Towards solutions of single-walled carbon nanotubes in common solvents, Adv. Mater. 20 (2008) 18761881.

[11] S. D. Bergin, Z. Sun, D. Rickard, P. V. Streich, J. P. Hamilton, J. N. Coleman, Multicomponent solubility parameters for single-walled carbon nanotubes-solvent mixtures, ACS Nano 3 (2009) 2340-2350.

[12] J. J. Jasper, The surface tension of pure liquid compounds, J. Phys. Chem. Ref. Data 1 (1972) 841-1009.

[13] J. A. Dean, Lange's Book of Chemistry, Fifteenth Edition, McGraw-Hill, Inc. (1998).

[14] C. M. Hansen, Hansen Solubility Parameters: A User's Handbook, Second Edition, CRC press, Taylor \& Francis group (2007).

[15] J. Brandrup, E. H. Immergut, E. A. Grulke,, A. Abe, D. R. Bloch, Polymer Handbook, Fourth Edition, John Wiley \& Sons, Inc., Wiley-interscience publication (1999).

[16] P. Weerachanchai, Z. Chen, S. S. J. Leong, M. W. Chang, J.M. Lee, Hildebrand solubility parameters of ionic liquids: Effects of ionic liquid type, temperature and DMA fraction in ionic liquid, Chem. Eng. J. 213 (2012) 356-362. 